Check for updates

Cite this: RSC Adv., 2019, 9, 24942

\title{
Biological activity evaluation and action mechanism of chalcone derivatives containing thiophene sulfonate $\uparrow$
}

\author{
Tao Guo, Rongjiao Xia, Mei Chen, Jun He, Shijun Su, Liwei Liu, Xiangyang Li \\ and Wei Xue (iD*
}

A series of novel chalcone derivatives containing a thiophene sulfonate group were designed and synthesized. The structures of all title compounds were determined by ${ }^{1} \mathrm{H}-\mathrm{NMR},{ }^{13} \mathrm{C}-\mathrm{NMR}$ and HRMS. Antibacterial bioassays indicated that, compound $2 \mathrm{l}$ demonstrated excellent antibacterial activities against Xanthomonas axonopodis pv. citri (Xac), with an $\mathrm{EC}_{50}$ value of $11.4 \mu \mathrm{g} \mathrm{mL}^{-1}$, which is significantly superior to those of bismerthiazol (BT) $\left(51.6 \mu \mathrm{g} \mathrm{mL}\right.$ ) and thiodiazole-copper (TC) $\left(94.7 \mu \mathrm{g} \mathrm{mL}^{-1}\right.$ ). Meanwhile, the mechanism of action of compound 21 was confirmed by using scanning electron microscopy (SEM). In addition, compound $2 \mathrm{e}$ showed remarkable inactivation activity against Tobacco mosaic virus (TMV), with an $\mathrm{EC}_{50}$ value of $44.3 \mu \mathrm{g} \mathrm{mL}^{-1}$, which was superior to that of ningnanmycin $\left(120.6 \mu \mathrm{g} \mathrm{mL}^{-1}\right.$ ). Microscale thermophoresis (MST) also showed that the binding of compounds $2 \mathrm{e}$ and $2 \mathrm{~h}$ to Tobacco mosaic virus coat protein (TMV-CP) yielded $K_{\mathrm{d}}$ values of 0.270 and $0.301 \mu \mathrm{mol} \mathrm{L}{ }^{-1}$, which are better than that of ningnanmycin $\left(0.596 \mu \mathrm{mol} \mathrm{L}{ }^{-1}\right)$. At the same time, molecular docking studies for $2 \mathrm{e}$ and $2 \mathrm{~h}$ with TMV-CP (PDB code: 1EI7) showed that the compound was embedded well in the pocket between the two subunits of TMV-CP in each case. These results suggested that chalcone derivatives containing a thiophene sulfonate group may be considered as activators in the design of antibacterial

Received 12th July 2019

Accepted 6th August 2019

DOI: $10.1039 / c 9 r a 05349 b$

rsc.li/rsc-advances and antiviral agents.

\section{Introduction}

The bacterial and virus infections of crops have become some of the world's most important agricultural problems, and the threat they pose is not only about agricultural production but also about human health. ${ }^{1-3}$ Pathogens that cause bacterial diseases, such as Xanthomonas oryzae pv. oryzae (Xoo), Ralstonia solanacearum (Rs) and Xanthomonas axonopodis pv. citri (Xac) ${ }^{4-6}$ are the world's most important and well-known plant bacteria. $^{7-11}$ These bacteria can actively suppress the crop yields worldwide. Besides, Tobacco mosaic virus (TMV), one of the world's most severe pathogenic viruses can infect a variety of crops, such as tobacco, cucumbers and other economic crops, resulting in a significant loss of crops each year. ${ }^{12-14}$ To overcome these serious problems, antibacterial drugs such as bismerthiazol (BT), thiodiazole-copper (TC), and ningnanmycin have been widely developed and used to reduce the infection by

State Key Laboratory Breeding Base of Green Pesticide and Agricultural Bioengineering, Key Laboratory of Green Pesticide and Agricultural Bioengineering, Ministry of Education, Center for Research and Development of Fine Chemicals, Guizhou University, Guiyang, 550025, China. E-mail: wxue@gzu.edu.cn; Fax: +86851-88292090; Tel: +86-851-88292090

$\dagger$ Electronic supplementary information (ESI) available. See DOI: 10.1039/c9ra05349b bacteria and plant viruses. ${ }^{15-17}$ However, prolonged use and abuse of traditional antibacterial drugs lead to increased resistance of pathogenic genes, which not only enhances the resistance of target pathogens but is also harmful to the environment and health of the plant. ${ }^{18-20}$ Therefore, the development of new antibacterial and antiviral agents is an important task in pesticide science.

Recent studies have shown that chalcone readily binds to receptors of different structures to form chalcone derivatives due to its flexible structure. ${ }^{21-23}$ Its derivatives have bactericidal, ${ }^{24,25}$ insecticidal, ${ }^{26,27}$ anticancer, ${ }^{28}$ antiviral, ${ }^{29,30}$ and antiinflammatory ${ }^{31}$ activities, thus demonstrating a wide range of applications in chemical and biological research. Thiophene sulfonate plays a prominent role in the studies and applications of organic chemistry. ${ }^{32,33}$ As a biologically important active intermediate, it is often used to synthesize thiophene sulfonate compounds with various biological activities. ${ }^{34-36}$ Therefore, thiophene sulfonate and its derivatives have a wide range of applications in industry, agriculture, pharmaceuticals and have a broad spectrum of biological activities, such as insecticidal, ${ }^{37,38}$ anti-inflammatory, ${ }^{39,40}$ antiviral, ${ }^{41,42}$ and anticancer. ${ }^{43}$

However, to the best of our knowledge, there have been no reports on chalcone-based thiophene sulfonates so far. To find excellent biological activities and environment-friendly small organic molecules, thiophene sulfonate structure with excellent 
biological activity is combined with the structure of chalcone by active splicing to design and synthesize a series of novel molecules. Through biological activity screening, it is expected to find chalcone compounds with high anti-plant viral and antibacterial activities, which lays a theoretical foundation for the creation of new pesticides.

\section{Experimental}

\subsection{Instrument, chemicals and reagents}

The molecular docking was performed by using DS-CDocker implemented in Discovery Studio (version 4.5). Melting points of the synthesized compounds (2a-2v) were measured using XT4 Binocular Microscope (Beijing Tech. Instrument, China) without correction. ${ }^{1} \mathrm{H}-\mathrm{NMR},{ }^{13} \mathrm{C}-\mathrm{NMR}$ and ${ }^{19} \mathrm{~F}-\mathrm{NMR}$ spectra were obtained on a Bruker Ascend-400 spectrometer (Bruker Optics, Switzerland) and DMSO- $d_{6}$ or $\mathrm{CDCl}_{3}$ were used as a solvent and TMS was used as an internal standard. HRMS data were obtained using Thermo Scientific Q Exactive Hybrid Quadrupole Mass Spectrometer (Thermo Scientific Inc., St Louis, MO, USA). The microscale thermophoresis (MST) of the compounds to check the interaction with TMV-CP (Tobacco mosaic virus coat protein) was determined using a micro thermophoresis instrument (NanoTemper Technologies $\mathrm{GmbH}$, Germany). All reagents and solvents were purchased from Chinese Chemical Reagent Company and were chemically pure analytical grade reagents. The synthetic route of chalcone derivatives containing thiophene sulfonate is shown in Scheme 1. The intermediate $\mathbf{1}$ were prepared according to the methods already reported in the literature. ${ }^{\mathbf{4 4}}$

\subsection{General procedure for the synthesis of intermediate 1}

At first, aqueous sodium hydroxide solution $(5 \% \mathrm{NaOH}, 5$ mmol) was added to a round-bottomed flask containing 1-(4hydroxyphenyl)ethan-1-one $(4 \mathrm{mmol})$ and differently substituted aldehydes ( $6 \mathrm{mmol})$. The mixture was stirred at ambient temperature for $12 \mathrm{~h}$. The resulting dark-yellow mixture was acidified by $\mathrm{HCl}(5 \% \mathrm{HCl}, 5 \mathrm{mmol})$ after the reaction was completed. Finally, the mixture was filtered under vacuum, and the residue was dried to yield intermediate $\mathbf{1}$.

\subsection{General procedure for the synthesis of title compounds} $2 a-2 v$

A solution of intermediate $1(6.5 \mathrm{mmol})$ and 2-thiophenesulfonyl chloride $(5.5 \mathrm{mmol})$ in acetonitrile $(50 \mathrm{~mL})$ was stirred until dissolved, the reaction mixture was refluxed at $90{ }^{\circ} \mathrm{C}$ for $10 \mathrm{~h}$. After completion of the reaction, the whole reaction system was poured into water, extracted with ethyl acetate, the solvent was removed under depressurization, and the residue was purified by column chromatography on silica gel with a mixture (v(petroleum ether) $: \mathrm{v}($ ethyl acetate $)=3: 1$ ) to yield the title compounds $2 \mathbf{a}-2 \mathbf{v} .{ }^{45}$ The ${ }^{1} \mathrm{H}-\mathrm{NMR},{ }^{13} \mathrm{C}-\mathrm{NMR}$, ${ }^{19}$ F-NMR and HMRS spectra of the designated title compounds $2 \mathbf{a}-\mathbf{2 v}$ are also provided in the ESI. $\dagger$

\section{Results and discussion}

\subsection{Spectral properties}

The structures of all the compounds were confirmed using ${ }^{1} \mathrm{H}$ NMR, ${ }^{13} \mathrm{C}-\mathrm{NMR}$ and HRMS. In ${ }^{1} \mathrm{H}-\mathrm{NMR}$ spectra, multiplet signals at $\delta 8.27-7.26 \mathrm{ppm}$ indicate the presence of protons in olefinic bonds and aromatic nuclei. The ${ }^{13} \mathrm{C}-\mathrm{NMR}$ spectra of the title compounds exhibited a characteristic $(\mathrm{C}=\mathrm{O})$ signal at $\delta$ 186.79-188.77 ppm. The ${ }^{13} \mathrm{C}-\mathrm{NMR}$ spectra of the title compounds exhibited a characteristic (thiophene-2-C) signal at $\delta$ 142.22-145.08 ppm. The strong presence of $[\mathrm{M}+\mathrm{H}]^{+}$ions indicates that the title compounds are in the steady state.

\subsection{Antibacterial activity of title compounds against Xac, Xoo and Rs in vitro}

The in vitro antibacterial activities of the title compounds $\mathbf{2 a - 2 v}$ against three phytopathogenic bacteria (Xac, Xoo and Rs) were tested by using turbidimeter. ${ }^{\mathbf{4 6}-48}$ Commercial agricultural bactericides (TC and BT) were used as the control, as shown in Table 1, and most of the compounds exhibited significant antibacterial activities against Xac, Xoo and Rs at 100 or $50 \mu \mathrm{g}$ $\mathrm{mL}^{-1}$. Among these, the antibacterial activities of the compounds 2e, $2 \mathbf{l}$ and $2 \mathbf{p}$ against Xac at $100 \mu \mathrm{g} \mathrm{mL}^{-1}$ were 77.2, 95.2 and $79.6 \%$, respectively, which exceeded both TC $(57.2 \%)$ and BT (65.3\%). Compounds 2a, 2f, 2j, 2l, 2m, 2o, 2q and $2 \mathbf{u}$ against Xoo at $50 \mu \mathrm{g} \mathrm{mL}{ }^{-1}$ were $65.6,60.8,46.4,58.0,58.4,58.5$, 56.9 and $62.2 \%$, respectively, which were better compared to TC $(37.2 \%)$ and $\mathrm{BT}(45.2 \%)$. In particular, the antibacterial<smiles>[R]C=CC(=O)c1ccc(OS(=O)(=O)c2cccs2)cc1</smiles>

2a: $\mathrm{R}=\mathrm{Ph}$; 2e: $\mathrm{R}=2-\mathrm{F}-\mathrm{Ph}$;

2i: $\mathrm{R}=3-\mathrm{Br}-\mathrm{Ph}$;

2m: $\mathrm{R}=3-\mathrm{CH}_{3}-\mathrm{Ph}$;

2q: $\mathrm{R}=2,4-$ di-Cl-Ph;

2u: $\mathrm{R}=3,4-$ di- $\mathrm{CH}_{3}-\mathrm{Ph}$ 2b: $\mathrm{R}=4-\mathrm{Cl}-\mathrm{Ph}$;

2f: $\mathrm{R}=3-\mathrm{F}-\mathrm{Ph}$;

2j: $\mathrm{R}=4-\mathrm{Br}-\mathrm{Ph}$;

2n: $\mathrm{R}=4-\mathrm{CH}_{3}-\mathrm{Ph}$;

2r: $\mathrm{R}=3,4-\mathrm{di}-\mathrm{Cl}-\mathrm{Ph}$
2v: $\mathrm{R}=2-\mathrm{OCH}_{3}-\mathrm{Ph}$. 2c: $\mathrm{R}=2-\mathrm{Cl}-\mathrm{Ph}$;

2g: $\mathrm{R}=4-\mathrm{F}-\mathrm{Ph}$;

2k: $\mathrm{R}=2-\mathrm{Py}$;

2o: $\mathrm{R}=3,4-\mathrm{di}-\mathrm{OCH}_{3}-\mathrm{Ph} ; \mathbf{2 p}: \mathrm{R}=2,4-\mathrm{di}-\mathrm{Cl}-\mathrm{Ph}$;

2s: $\mathrm{R}=\mathrm{C}_{3} \mathrm{H}_{7}-\mathrm{Ph}$; 2d: $\mathrm{R}=3-\mathrm{Cl}-\mathrm{Ph}$;

2h: $\mathrm{R}=2-\mathrm{Br}-\mathrm{Ph}$;

2l: $\mathrm{R}=2-\mathrm{NO}_{2}-\mathrm{Ph}$

2t: $\mathrm{R}=4-\mathrm{Py}$

Scheme 1 Synthetic route of title compounds $2 a-2 v$. 
Table 1 Antibacterial activities of title compounds (2a-2v) against plant pathogens $\mathrm{Xac}$, Xoo and Rs in vitro

\begin{tabular}{|c|c|c|c|c|c|c|c|}
\hline \multirow[b]{2}{*}{ Compounds } & \multirow[b]{2}{*}{$\mathrm{R}$} & \multicolumn{2}{|l|}{ Xac (\%) } & \multicolumn{2}{|l|}{ Xoo (\%) } & \multicolumn{2}{|l|}{ Rs (\%) } \\
\hline & & $\mathrm{mL}^{-1}$ & $50 \mu \mathrm{g} \mathrm{mL}^{-1}$ & $100 \mu \mathrm{g} \mathrm{mL}^{-1}$ & $50 \mu \mathrm{g} \mathrm{mL}^{-1}$ & $100 \mu \mathrm{g} \mathrm{mL}^{-1}$ & $50 \mu \mathrm{g} \mathrm{mL} L^{-1}$ \\
\hline $2 a$ & $\mathrm{Ph}$ & $67.5 \pm 1.7$ & $53.4 \pm 1.6$ & $72.4 \pm 1.7$ & $65.6 \pm 1.4$ & $76.6 \pm 1.4$ & $48.8 \pm 1.4$ \\
\hline $2 \mathbf{b}$ & 4-Cl-Ph & $59.3 \pm 2.5$ & $22.6 \pm 3.4$ & $62.6 \pm 1.3$ & $43.8 \pm 2.4$ & $47.1 \pm 3.7$ & $40.3 \pm 1.2$ \\
\hline $2 \mathrm{c}$ & 2-Cl-Ph & $45.3 \pm 3.1$ & $23.4 \pm 2.9$ & $52.9 \pm 3.6$ & $37.5 \pm 2.9$ & $53.3 \pm 2.9$ & $48.9 \pm 2.5$ \\
\hline $2 f$ & 3-F-Ph & $66.5 \pm 1.5$ & $44.6 \pm 2.4$ & $88.1 \pm 1.7$ & $60.8 \pm 2.6$ & $67.8 \pm 0.6$ & $55.1 \pm 1.6$ \\
\hline $2 \mathrm{~g}$ & 4-F-Ph & $63.5 \pm 1.5$ & $55.2 \pm 1.9$ & $43.2 \pm 1.3$ & $39.4 \pm 1.6$ & $58.3 \pm 1.5$ & $48.8 \pm 1.3$ \\
\hline $2 h$ & 2-Br-Ph & $52.9 \pm 2.2$ & $36.8 \pm 0.9$ & $53.3 \pm 0.9$ & $35.7 \pm 3.7$ & $52.6 \pm 3.8$ & $33.0 \pm 0.8$ \\
\hline $2 \mathbf{i}$ & 3-Br-Ph & $46.5 \pm 2.9$ & $32.4 \pm 3.5$ & $36.0 \pm 2.1$ & $24.3 \pm 1.4$ & $40.8 \pm 5.6$ & $33.5 \pm 1.9$ \\
\hline $2 \mathbf{j}$ & 4-Br-Ph & $52.5 \pm 2.7$ & $25.6 \pm 1.7$ & $77.3 \pm 0.4$ & $46.4 \pm 2.6$ & $56.7 \pm 2.4$ & $43.4 \pm 2.5$ \\
\hline $2 k$ & 2-Py & $59.7 \pm 1.2$ & $32.6 \pm 1.8$ & $43.2 \pm 0.6$ & $32.9 \pm 1.2$ & $73.7 \pm 7.9$ & $56.3 \pm 2.0$ \\
\hline $2 p$ & 2,4-di-Cl-Ph & $79.6 \pm 0.5$ & $56.4 \pm 1.1$ & $44.6 \pm 1.8$ & $34.2 \pm 0.9$ & $85.2 \pm 0.5$ & $56.6 \pm 2.0$ \\
\hline $2 q$ & 3,4-di-Cl-Ph & $55.6 \pm 2.5$ & $18.7 \pm 1.4$ & $68.2 \pm 1.1$ & $56.9 \pm 1.8$ & $57.2 \pm 1.3$ & $47.2 \pm 2.6$ \\
\hline $2 \mathbf{r}$ & $\mathrm{C}_{3} \mathrm{H}_{7}-\mathrm{Ph}$ & $59.4 \pm 1.4$ & $21.4 \pm 0.2$ & $44.6 \pm 1.8$ & $34.2 \pm 0.9$ & $52.8 \pm 1.6$ & $32.2 \pm 1.3$ \\
\hline $2 s$ & 2-Th & $52.3 \pm 2.1$ & $38.7 \pm 1.6$ & $55.6 \pm 0.4$ & $41.8 \pm 2.7$ & $50.6 \pm 1.7$ & $42.5 \pm 1.8$ \\
\hline $2 t$ & 4-Py & $46.3 \pm 0.8$ & $26.1 \pm 3.8$ & $36.7 \pm 1.9$ & $25.9 \pm 4.5$ & $45.3 \pm 3.2$ & $37.6 \pm 2.4$ \\
\hline $2 u$ & 3,4-di- $\mathrm{CH}_{3}-\mathrm{Ph}$ & $52.4 \pm 1.2$ & $32.5 \pm 1.4$ & $83.3 \pm 0.8$ & $62.2 \pm 1.0$ & $66.3 \pm 0.3$ & $58.2 \pm 0.9$ \\
\hline $2 \mathbf{v}$ & $2-\mathrm{OCH}_{3}-\mathrm{Ph}$ & $56.2 \pm 1.8$ & $31.1 \pm 1.9$ & $56.7 \pm 2.4$ & $43.4 \pm 2.5$ & $42.3 \pm 1.3$ & $28.3 \pm 2.5$ \\
\hline $\mathrm{TC}^{a}$ & - & $57.2 \pm 1.3$ & $27.8 \pm 3.8$ & $50.2 \pm 0.9$ & $37.2 \pm 3.2$ & $45.2 \pm 4.3$ & $20.6 \pm 2.7$ \\
\hline $\mathrm{BT}^{a}$ & - & $65.3 \pm 2.8$ & $54.9 \pm 5.5$ & $64.9 \pm 3.9$ & $45.2 \pm 2.0$ & $53.7 \pm 3.6$ & $32.2 \pm 2.8$ \\
\hline
\end{tabular}

${ }^{a}$ The commercial agricultural antibacterial agents thiodiazole copper (TC) and bismerthiazol (BT) were used as control agents.

Table $2 \mathrm{EC}_{50}$ values of the title compounds against plant pathogenic bacteria in vitro

\begin{tabular}{|c|c|c|c|c|c|}
\hline \multirow[t]{4}{*}{ Xac } & $2 e$ & 2-F-Ph & $y=1.2997 x+2.9498$ & 0.9862 & 46.5 \\
\hline & 21 & $3-\mathrm{NO}_{2}-\mathrm{Ph}$ & $y=1.5536 x+2.7744$ & 0.9872 & 11.4 \\
\hline & $\mathrm{TC}^{a}$ & - & $y=1.1576 x+2.7122$ & 0.9859 & 94.7 \\
\hline & $\mathrm{BT}^{a}$ & - & $y=1.0698 x+3.1679$ & 0.9831 & 51.6 \\
\hline \multirow[t]{7}{*}{ Xoo } & $2 a$ & $\mathrm{Ph}$ & $y=0.8781 x+3.8623$ & 0.9842 & 19.8 \\
\hline & 21 & $3-\mathrm{NO}_{2}-\mathrm{Ph}$ & $y=1.4387 x+2.9155$ & 0.9778 & 28.1 \\
\hline & $2 \mathrm{~m}$ & $3-\mathrm{CH}_{3}-\mathrm{Ph}$ & $y=1.0376 x+3.3799$ & 0.9891 & 21.8 \\
\hline & 20 & 3,4-di- $-\mathrm{OCH}_{3}-\mathrm{Ph}$ & $y=1.1362 x+3.2891$ & 0.9981 & 32.0 \\
\hline & $2 q$ & 3,4-di-Cl-Ph & $y=1.3694 x+2.8072$ & 0.9876 & 39.9 \\
\hline & $2 \mathbf{u}$ & 3,4-di- $\mathrm{CH}_{3}-\mathrm{Ph}$ & $y=1.6774 x+2.5248$ & 0.9928 & 29.8 \\
\hline & $\mathrm{TC}^{a}$ & - & $y=1.2058 x+2.2869$ & 0.9971 & 97.8 \\
\hline & $2 \mathbf{k}$ & 2-Py & $y=1.4622 x+2.6783$ & 0.9975 & 38.7 \\
\hline & $2 \mathrm{~m}$ & $3-\mathrm{CH}_{3}-\mathrm{Ph}$ & $y=1.3326 x+3.5835$ & 0.9814 & 11.6 \\
\hline & $2 n$ & $4-\mathrm{CH}_{3}-\mathrm{Ph}$ & $y=0.9189 x+3.5445$ & 0.9775 & 38.4 \\
\hline & 20 & 3,4-di- $\mathrm{OCH}_{3}-\mathrm{Ph}$ & $y=1.9357 x+2.2953$ & 0.9886 & 25.0 \\
\hline & $2 p$ & 2,4-di-Cl-Ph & $y=1.7032 x+2.4391$ & 0.9758 & 31.9 \\
\hline & $2 \mathbf{u}$ & 3,4 -di- $\mathrm{CH}_{3}-\mathrm{Ph}$ & $y=1.0373 x+3.3816$ & 0.9864 & 36.3 \\
\hline & $\mathrm{TC}^{a}$ & - & $y=1.4682 x+1.8274$ & 0.9758 & 78.8 \\
\hline & $\mathrm{BT}^{a}$ & - & $y=1.2581 x+2.4918$ & 0.9746 & 98.6 \\
\hline
\end{tabular}

${ }^{a}$ The commercial agricultural antibacterial agents thiodiazole copper (TC) and bismerthiazol (BT) were used as control agents. 

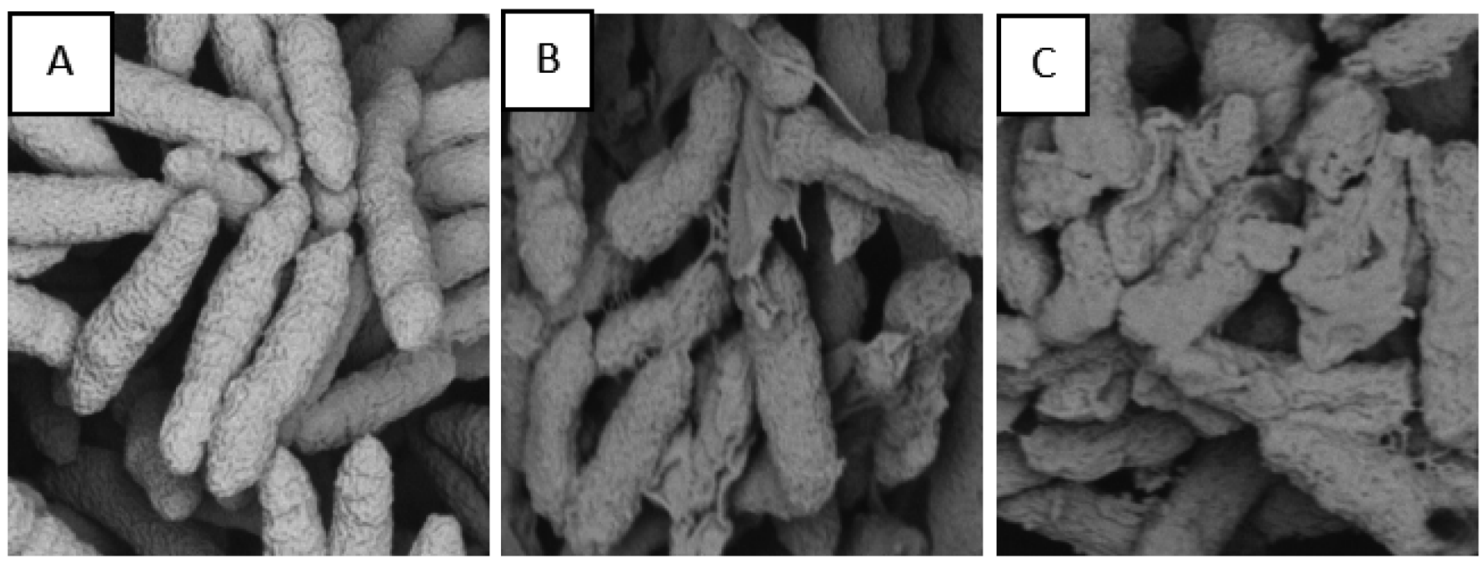

Fig. 1 SEM images for Xac after incubated using different concentrations of compound $2 \mathrm{l}$, (A) $0 \mu \mathrm{g} \mathrm{mL} \mathrm{L}^{-1}$, (B) $50 \mu \mathrm{g} \mathrm{m} \mathrm{L}^{-1} \mathrm{and}$ (C) $100 \mu \mathrm{g} \mathrm{mL}$. Scale bar for (A), (B) and (C) are $2 \mu \mathrm{m}$.

activities of the compounds $2 \mathbf{m}, 2 \mathrm{o}$ and $2 \mathrm{p}$ against Rs at 100 and $50 \mu \mathrm{g} \mathrm{mL}^{-1}$ were 91.4 and $77.5 \%, 92.4$ and $63.3 \%, 85.2$ and $56.6 \%$, respectively, which were significantly superior to TC (45.2 and 20.6\%) and BT (53.7 and 32.2\%).

The antibacterial activities of the compounds were further confirmed by determining their $\mathrm{EC}_{50}$ values, and the obtained results are shown in Table 2. Compounds $2 \mathbf{e}, \mathbf{2 l}$ and $\mathbf{2 p}$ exhibited remarkable antibacterial activities against Xac, with $\mathrm{EC}_{50}$ values of $46.5,11.4$, and $27.1 \mu \mathrm{g} \mathrm{mL} \mathrm{L}^{-1}$, which were much better compared to TC $\left(94.7 \mu \mathrm{g} \mathrm{mL}^{-1}\right)$ and BT $\left(51.6 \mu \mathrm{g} \mathrm{mL}^{-1}\right)$. Compounds 2a, 2f, 2j, 2l, 2m, 2o, 2q and $2 \mathbf{u}$ exhibited excellent antibacterial activities against Xoo, with $\mathrm{EC}_{50}$ values of 19.8, 19.1, 42.6, 28.1, 21.8, 32.0, 39.9 and $29.8 \mu \mathrm{g} \mathrm{mL} \mathrm{m}^{-1}$, respectively which were significantly superior to TC $\left(97.8 \mu \mathrm{g} \mathrm{mL}^{-1}\right)$ and BT $\left(71.7 \mu \mathrm{g} \mathrm{mL}^{-1}\right)$. Compounds 2a, 2e, 2f, 2k, 2m, 2n, 2o, 2p and $2 \mathbf{u}$ exhibited notable antibacterial activities against Rs, with $\mathrm{EC}_{50}$ values of 38.4, 38.9, 43.6, 38.7, 11.6, 38.4, 25.0, 31.9 and $36.3 \mu \mathrm{g}$ $\mathrm{mL}^{-1}$, respectively, which were much better than TC $(98.6 \mu \mathrm{g}$ $\left.\mathrm{mL}^{-1}\right)$ and BT $\left(78.8 \mu \mathrm{g} \mathrm{mL}^{-1}\right)$. These results indicate that such compounds should be further studied as potential alternative templates in the search for novel antibacterial agents.

\subsection{Structure-activity relationships of antibacterial activities}

Tables 1 and 2 show that the changes in the substituted groups could significantly impact the inhibitory effects against plant

Table 3 Antiviral activities of the test compounds against TMV in vivo at $500 \mu \mathrm{gL}^{-1}$

\begin{tabular}{|c|c|c|c|c|}
\hline Compounds & $\mathrm{R}$ & Curative activity $^{a}(\%)$ & Protective activity $^{a}(\%)$ & Inactivation activity $^{a}(\%)$ \\
\hline $2 a$ & $\mathrm{Ph}$ & $72.5 \pm 2.5$ & $67.0 \pm 2.1$ & $80.1 \pm 1.7$ \\
\hline $2 \mathbf{b}$ & 4-Cl-Ph & $46.4 \pm 2.6$ & $58.3 \pm 0.9$ & $53.8 \pm 2.2$ \\
\hline $2 d$ & 3-Cl-Ph & $45.3 \pm 3.8$ & $51.9 \pm 2.2$ & $59.7 \pm 2.3$ \\
\hline $2 e$ & 2-F-Ph & $76.2 \pm 1.2$ & $70.2 \pm 1.9$ & $87.3 \pm 0.7$ \\
\hline $2 f$ & 3-F-Ph & $48.5 \pm 0.9$ & $35.3 \pm 2.2$ & $60.2 \pm 1.5$ \\
\hline $2 \mathbf{i}$ & 3-Br-Ph & $26.9 \pm 1.8$ & $54.6 \pm 4.4$ & $65.3 \pm 3.1$ \\
\hline $2 \mathbf{j}$ & 4-Br-Ph & $48.4 \pm 0.8$ & $61.9 \pm 2.5$ & $58.9 \pm 1.7$ \\
\hline $2 \mathbf{k}$ & 2-Py & $45.6 \pm 1.6$ & $42.9 \pm 1.9$ & $66.1 \pm 1.8$ \\
\hline 21 & $3-\mathrm{NO}_{2}-\mathrm{Ph}$ & $74.8 \pm 1.7$ & $69.8 \pm 1.6$ & $75.3 \pm 2.4$ \\
\hline $2 \mathrm{~m}$ & $3-\mathrm{CH}_{3}-\mathrm{Ph}$ & $72.6 \pm 1.9$ & $52.8 \pm 0.7$ & $69.2 \pm 0.7$ \\
\hline $2 n$ & $4-\mathrm{CH}_{3}-\mathrm{Ph}$ & $30.3 \pm 1.6$ & $35.4 \pm 2.9$ & $45.3 \pm 2.7$ \\
\hline $2 \mathrm{~s}$ & 2 -Th & $48.7 \pm 4.3$ & $32.1 \pm 1.9$ & $54.2 \pm 1.7$ \\
\hline $2 t$ & 4-Py & $43.9 \pm 2.8$ & $57.6 \pm 1.7$ & $56.2 \pm 3.8$ \\
\hline $2 \mathbf{u}$ & 3,4 -di- $\mathrm{CH}_{3}-\mathrm{Ph}$ & $49.3 \pm 1.9$ & $36.3 \pm 1.8$ & $61.2 \pm 0.9$ \\
\hline $2 v$ & $2-\mathrm{OCH}_{3}-\mathrm{Ph}$ & $53.0 \pm 1.8$ & $51.1 \pm 2.6$ & $45.2 \pm 1.4$ \\
\hline Ningnanmycin ${ }^{b}$ & - & $53.3 \pm 1.2$ & $62.6 \pm 1.3$ & $78.3 \pm 1.5$ \\
\hline
\end{tabular}

${ }^{a}$ Average of three replicates. ${ }^{b}$ The commercial antiviral agent ningnanmycin. 
Table 4 EC 50 values of some compounds against TMV

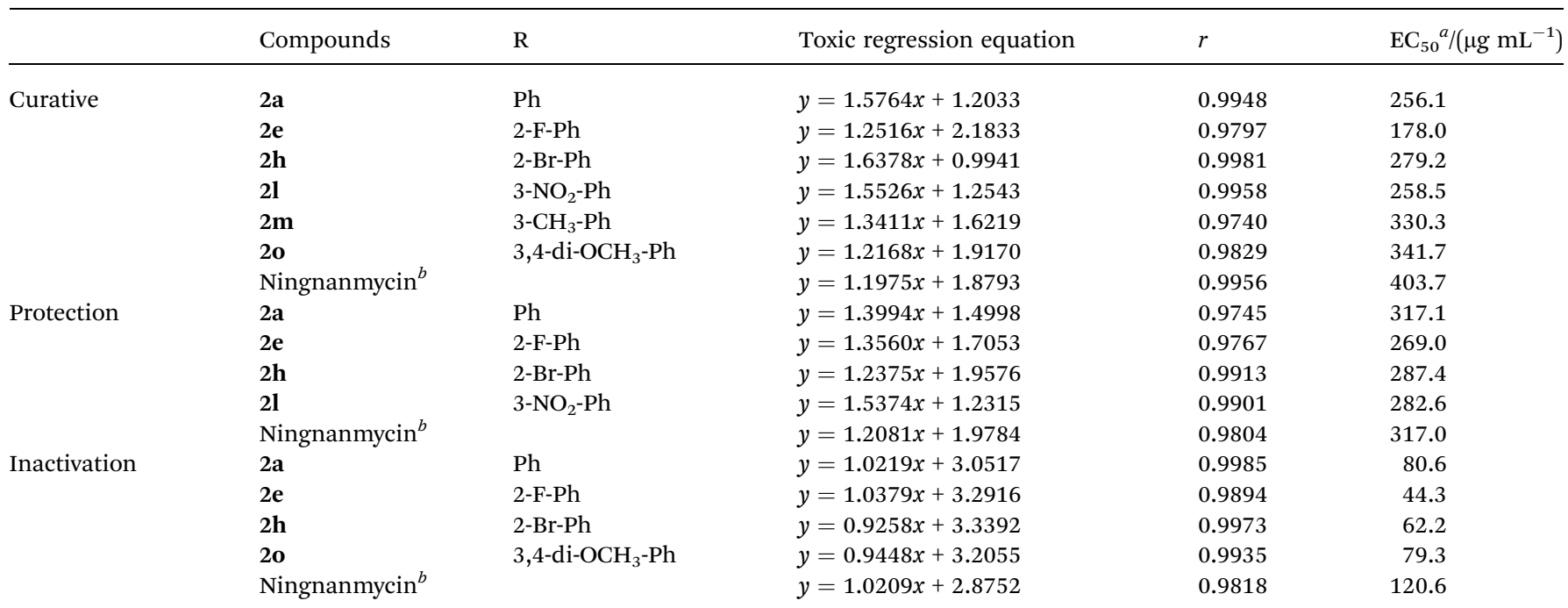

${ }^{a}$ Average of three replicates. ${ }^{b}$ The commercial antiviral agent ningnanmycin.

bacteria, and analysis on the structure-activity relationships is discussed below. For instance, the designated compounds $2 \mathbf{e}(\mathrm{R}$ $=2-\mathrm{F}-\mathrm{Ph}), 2 \mathbf{l}\left(\mathrm{R}=3-\mathrm{NO}_{2}-\mathrm{Ph}\right)$ and $2 \mathrm{p}(\mathrm{R}=2,4$-di-Cl-Ph $)$ exhibited significant anti Xac at $100 \mu \mathrm{g} \mathrm{mL}{ }^{-1}$, with the inhibition rates of $77.2,95.2$ and $79.6 \%$, respectively. These compounds were found to be more active compared to other tested compounds. However, when $\mathrm{R}$ was substituted with $\mathrm{Ph}, 3-\mathrm{F}-\mathrm{Ph}, 4-\mathrm{Br}-\mathrm{Ph}, 3-$ $\mathrm{NO}_{2}-\mathrm{Ph}, 3,4-\mathrm{di}-\mathrm{OCH}_{3}-\mathrm{Ph}$, and 3,4-di- $\mathrm{CH}_{3}-\mathrm{Ph}$ groups, the activities of the corresponding compounds $2 \mathbf{a}, 2 \mathbf{f}, 2 \mathbf{j}, 2 \mathbf{l}, 2 \mathbf{o}$ and $2 \mathbf{u}$, against Xoo at $100 \mu \mathrm{g} \mathrm{mL} \mathrm{mL}^{-1}$ were 72.4, 88.1, 77.3, 82.3, 72.3 and $83.3 \%$, respectively, which were higher than that of bismerthiazol (64.9\%) and thiadiazole-copper (50.2\%). Notably, when R groups was $\mathrm{Ph}(\mathbf{2 a}), 3-\mathrm{F}-\mathrm{Ph}(\mathbf{2 e}), 2-\mathrm{Py}(\mathbf{2 k}), 3-\mathrm{CH}_{3}-\mathrm{Ph}(\mathbf{2 m}), 3,4-$ di- $\mathrm{OCH}_{3}-\mathrm{Ph}$ (2o) and 2,4-di-Cl-Ph (2p) excellent biological activity was found anti Rs at $100 \mu \mathrm{g} \mathrm{mL}^{-1}$, inhibition rates of 76.6, 71.1, 73.7, 91.4, 92.4 and $85.2 \%$, respectively.

\subsection{Scanning electron microscopy (SEM) study}

Following the antibacterial activities of the compounds, as shown in Tables 1 and 2, the antibacterial mechanism of Xac was further studied through SEM analysis. ${ }^{49}$ It can be seen that the compound destroys the cell membrane, and more importantly, as the concentration of the compound increases, the damage of the cell membrane becomes more serious. For example, when the concentration was $50 \mu \mathrm{g} \mathrm{mL}^{-1}$, a part of the cell membrane begins to destroy (Fig. 1B). However, when the concentration was further increased to $100 \mu \mathrm{g} \mathrm{mL} \mathrm{L}^{-1}$, most of the cell membrane was damaged, and only a small number of cells was present (Fig. 1C). In contrast, in the absence of treatment with compound 2l, the cells were smooth and well stacked with an intact membrane (Fig. 1A). These SEM images further confirm that compound $2 \mathbf{l}$ destroys bacterial cells and may eventually kill the cells.

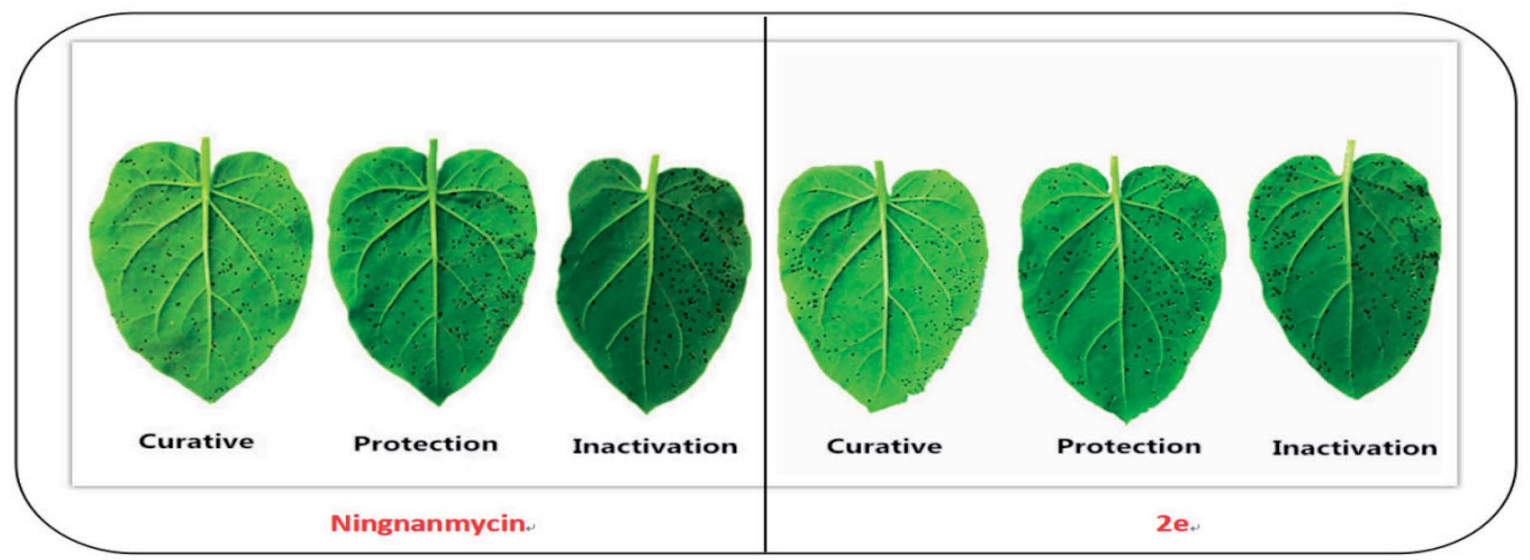

Fig. 2 Tobacco leaf morphology effects of the ningnanmycin and $2 \mathrm{e}$ against TMV in vivo. (Right leaf: not treated with compound; left leaf: smeared with compound). 

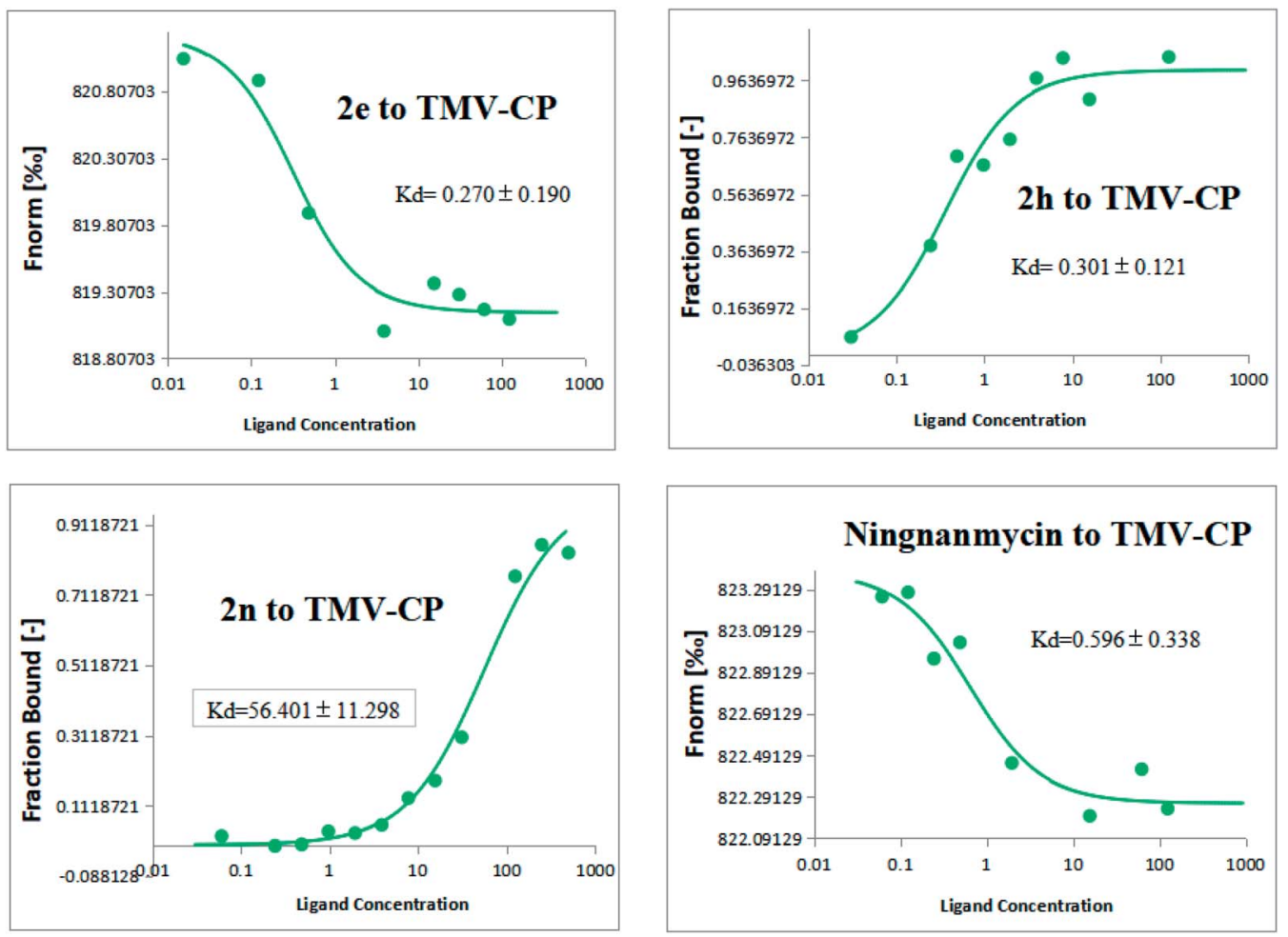

Fig. 3 Microscale thermophoresis (MST) results of compounds $2 \mathrm{e}, 2 \mathrm{~h}, 2 \mathrm{n}$ and ningnanmycin.

\subsection{Antiviral activity of title compounds against TMV in vivo}

Using the same age tobacco leaves as the test subjects, the in vivo healing and protective activities of TMV at $500 \mu \mathrm{g} \mathrm{mL}$ were assessed by the half-blight spot method. ${ }^{50-52}$ For this, a commercial agricultural antiviral agent ningnanmycin was used as a control, and the obtained preliminary bioassay results are shown in Table 3. The compounds exhibited significant antiviral activity against TMV. Among them, compounds 2a, 2e, 2h, 21, 2m and $2 \mathbf{o}$ showed excellent curative activities against TMV, with the inhibition of $72.5,84.2,73.5,81.8,72.6$ and $75.3 \%$, which were better than ningnanmycin $(53.3 \%)$. The protective activities of $2 \mathbf{a}, \mathbf{2 e}, \mathbf{2 h}$ and $2 \mathbf{l}$ (70.0, 75.2, 71.8 and $72.8 \%$, respectively) against TMV were more effective than ningnanmycin (62.6\%). In particularly, compounds $2 \mathbf{a}, \mathbf{2 e}, \mathbf{2 h}$ and 20 showed excellent inactivation activities against TMV, with the inhibition of $80.1,87.3,81.1$ and $79.8 \%$, which were better than ningnanmycin (78.3\%).

To compare the antiviral activity of the synthesized compounds (2a-2v), $\mathrm{EC}_{50}$ values of $2 \mathrm{a}, 2 \mathbf{e}, 2 \mathbf{h}, 2 \mathbf{l}, 2 \mathrm{~m}$ and $2 \mathbf{o}$ were calculated and have been summarized in Table 4 . It could be seen that compounds $\mathbf{2 a}, \mathbf{2 e}, \mathbf{2 h}$ and $\mathbf{2 l}$ exhibited higher curative activity than ningnanmycin $\left(403.7 \mu \mathrm{g} \mathrm{mL}^{-1}\right)$, with $\mathrm{EC}_{50}$ values of 256.1, 178.0, 279.2 and $258.5 \mu \mathrm{g} \mathrm{mL} \mathrm{mL}^{-1}$, respectively. Compounds $2 \mathrm{e}$ and $2 \mathrm{l}$ exhibited the best protective activity against TMV, with $\mathrm{EC}_{50}$ values of 269.0 and $282.6 \mu \mathrm{g} \mathrm{mL} \mathrm{m}^{-1}$, respectively, which were better than that of ningnanmycin $\left(317.0 \mu \mathrm{g} \mathrm{mL} \mathrm{m}^{-1}\right)$. Among them, compounds $2 \mathbf{e}$ and $2 \mathbf{h}$ exhibited the best inactivation activity against TMV, with $\mathrm{EC}_{50}$ values of 44.3 and $62.2 \mu \mathrm{g} \mathrm{mL}{ }^{-1}$, respectively, which were better than that of ningnanmycin $\left(120.6 \mu \mathrm{g} \mathrm{mL}{ }^{-1}\right)$. It can be indicated from these results that most of these novel chalcone derivatives containing thiophene sulfonate could be further studied as a potential alternative template in the search for novel antiviral agents (Fig. 2).

\subsection{Structure-activity relationships of antiviral activities}

As indicated in Tables 3 and 4, most of the thiophene sulfonate chalcone derivatives showed significant antiviral activities against TMV, and some of the structure-activity relationships can be analyzed and summarized. First, the $\mathrm{Ph}, 2-\mathrm{F}-\mathrm{Ph}, 2-\mathrm{Br}-\mathrm{Ph}$, $3-\mathrm{NO}_{2}-\mathrm{Ph}$ and $3-\mathrm{CH}_{3}-\mathrm{Ph}$ groups at $-\mathrm{R}$ position greatly improved the curative activities of the title compounds against TMV. For instance, the curative activities of the target compounds $\mathbf{2 a}, \mathbf{2 e}$, $\mathbf{2 h}, \mathbf{2 l}$ and $\mathbf{2 m}$, which were better than that of other substituent groups. In addition, when - $\mathrm{R}$ was $\mathrm{Ph}, 2-\mathrm{F}-\mathrm{Ph}, 2-\mathrm{Br}-\mathrm{Ph}$ and $3-\mathrm{NO}_{2}$ $\mathrm{Ph}$ groups, the protective activities of the corresponding compounds 2a, 2e, $2 \mathbf{h}$ and $2 \mathbf{l}$ at $500 \mu \mathrm{g} \mathrm{mL}{ }^{-1}$ were better than that of ningnanmycin. When $\mathrm{R}$ was with $\mathrm{Ph}(\mathbf{2 a}), 2-\mathrm{F}-\mathrm{Ph}(\mathbf{2 e}), 2-$ $\mathrm{Br}-\mathrm{Ph}(\mathbf{2 h})$ and 3,4-di-OCH $\mathrm{H}_{3} \mathrm{Ph}(\mathbf{2 o})$ groups, the corresponding compounds presented excellent inactivation activity against TMV. For instance, some target compounds the curative, protection and inactivation effects which were better than that of ningnanmycin following the order of $2 \mathrm{e}(\mathrm{R}=2-\mathrm{F}-\mathrm{Ph})>2 \mathrm{~h}(\mathrm{R}$ $=2-\mathrm{Br}-\mathrm{Ph})>2 \mathrm{a}(\mathrm{R}=\mathrm{Ph})$. The detailed values corresponding to these results can be seen in Table 3 .

\subsection{Binding sites of $2 \mathrm{e}, 2 \mathrm{~h}, 2 \mathrm{n}$ and ningnanmycin to TMV- CP}

To further analyze the interactions between the title compounds and TMV coat protein (TMV-CP), the microscale 


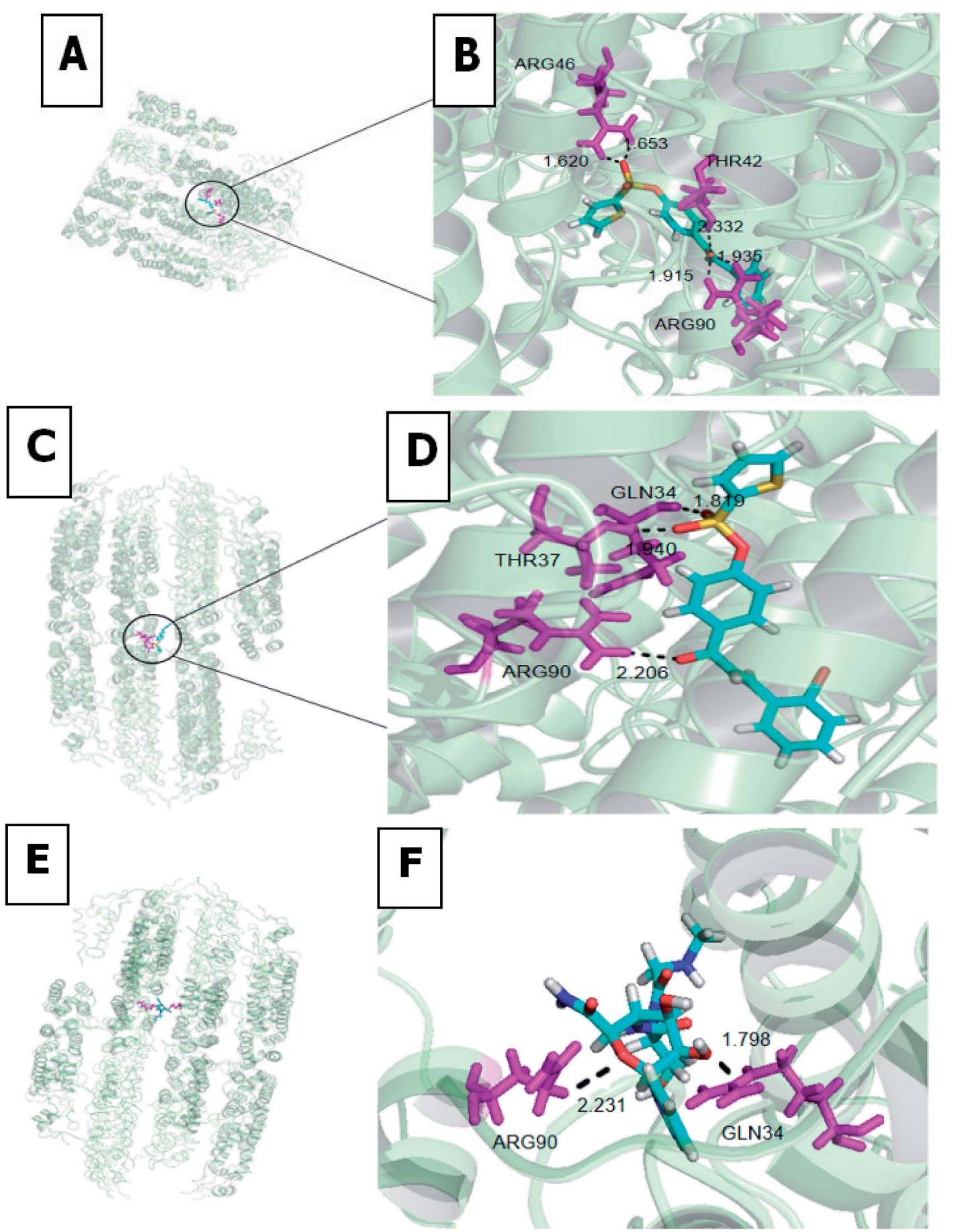

Fig. 4 Molecular docking studies of compounds $2 \mathrm{e}(\mathrm{A}$ and $\mathrm{B}), 2 \mathrm{~h}(\mathrm{C}$ and $\mathrm{D})$ and ningnanmycin ( $\mathrm{E}$ and $\mathrm{F})$.

thermophoresis (MST) analysis was used. ${ }^{53,54}$ The MST results as summarized in Fig. 3 show that the binding of compounds $2 \mathbf{e}$, 2h, 2n and ningnanmycin to TMV-CP protein yielded $K_{\mathrm{d}}$ values of $0.270 \pm 0.190 \mu \mathrm{mol} \mathrm{L}{ }^{-1}, 0.301 \pm 0.121 \mu \mathrm{mol} \mathrm{L}^{-1}, 56.401 \pm$ $11.298 \mu \mathrm{mol} \mathrm{L}^{-1}$ and $0.596 \pm 0.338 \mu \mathrm{mol} \mathrm{L}{ }^{-1}$, respectively. As indicated in MST, $2 \mathbf{e}$ or $\mathbf{2 h}$ with ningnanmycin share strong affinity, which is contrary to $2 \mathbf{n}$ as it shares weak affinity. These results exhibited that the combining capacity in the following order of $\mathbf{2 e}>\mathbf{2 h}>$ ningnanmycin $>\mathbf{2 n}$ is consistent with the trends of the screening of antiviral activities. Based on the experimental results it can be predicted that compounds $2 \mathbf{e}$ and 2h may interact with TMV-CP. As depicted in Fig. 3 the bioactivity was mainly determined by the electrostatic interactions, and the activity could have been enhanced by the presence of aromatic ring which is rich in electrons for absorption. For example, when $\mathrm{R}$ was substituted with $2-\mathrm{F}-\mathrm{Ph}$ and $2-\mathrm{Br}-\mathrm{Ph}$ groups, the corresponding compounds $2 \mathbf{e}$ and $\mathbf{2 h}$ exhibited a stronger combining capacity, with $K_{\mathrm{d}}$ values of $0.270 \pm 0.190$ 
$\mu \mathrm{mol} \mathrm{L}{ }^{-1}$ and $0.301 \pm 0.121 \mu \mathrm{mol} \mathrm{L}^{-1}$, as compared to that of compound $2 \mathbf{h}\left(56.401 \pm 11.298 \mu \mathrm{mol} \mathrm{L^{-1 }}\right)$, which was substituted with a $4-\mathrm{CH}_{3}-\mathrm{Ph}$.

\subsection{Molecular docking of $2 \mathrm{e}$ or $2 \mathrm{~h}$ and TMV-CP}

To identify the $2 \mathbf{e}$ and $\mathbf{2 h}$ recognition sites in TMV-CP (PDB code: 1EI7), we performed molecular docking using the Gold method with 200 cycles. As depicted in Fig. 4, the three compounds were well-embedded in the activity pocket (ARG-46, THR-42, ARG-90, GLN-34, THR-37, etc.) between the two subunits of TMV-CP. Among them, ARG-46 had strong hydrogen bond with $2 \mathrm{e}(1.620 \AA$ and $1.653 \AA), \mathrm{C}=\mathrm{O}(2 \mathrm{e})$ demonstrates three hydrogens with the THR-42 $(\mathrm{O}-\mathrm{H}=2.332$ $\AA)$, ARG-90 (O-H = $1.915 \AA$ and $1.935 \AA$ A $)$. Moreover, thiophene sulfonate demonstrates strong hydrogen bond with GLN-34 (O$\mathrm{H}=1.819 \AA)$, THR-37 showed one hydrogen bond $2 \mathbf{h}(1.940 \AA)$, there was also one hydrogen bond between the $\mathrm{C}=\mathrm{O}$ and the residue ARG-90 $(\mathrm{O}-\mathrm{H}=2.206 \AA)$. In addition, GLN-34 had strong hydrogen bond with ningnanmycin $(1.798 \AA), \mathrm{C}=\mathrm{O}$ (ningnanmycin) demonstrates one hydrogens with the ARG-90 $(2.231 \AA)$. It can be seen that the combination of $2 \mathbf{e}$ and $2 \mathbf{h}$ with TMV-CP has several more stable hydrogen bonds than ningnanmycin and TMV-CP, thus indicating that $2 \mathbf{e}$ and $\mathbf{2 h}$ have better antiviral activity than ningnanmycin. These interactions between molecules and TMV-CP are likely to weaken the interaction of two subunits of TMV-CP, thereby preventing the self-assembly of TMV particle, as well as the binding capability with TMV-CP. The results of molecular docking studies were consistent with the experimental results (protection and curative activities) and support that the chalcone derivatives containing thiophene sulfonate may be potential lead structures for developing novel anti-TMV agents.

\section{Conclusions}

In summary, with the aim of developing a novel, highly efficient, and environmentally benign virucide, in this study a thiophene sulfonate group was introduced into chalcone derivatives to synthesize 22 derivatives. Also, their in vitro antibacterial activities against Xac, Xoo, and Rs and their in vivo antiviral activity against TMV were evaluated. Bioassay results showed that several of the title compounds exhibited good antibacterial and antiviral activities. In particular, compound $2 \mathbf{l}$ showed remarkable activity against Xac. Among them, compounds 2a, $2 \mathbf{e}, 2 \mathbf{h}, 2 \mathbf{l}, 2 \mathbf{m}$ and $2 \mathbf{o}$ showed excellent curative activities against TMV. Based on the above results, these novel thiophene sulfonate chalcone derivatives should be further studied as potential alternative templates in the search for novel antibacterial and antiviral agents.

\section{Conflicts of interest}

The authors declare that they have no competing interests.

\section{Acknowledgements}

This research was funded by the National Key Research and Development Program of China (No. 2017YFD0200506) and the Science and Technology Project of Guizhou Province (No. 20185781).

\section{References}

1 Z. F. Li, S. L. Wu, X. F. Bai, Y. Liu, J. F. Lu, Y. Liu, B. G. Xiao, X. P. Lu and L. Fan, J. Bacteriol., 2011, 193, 6088-6089.

2 F. D. Lorenzo, A. Palmigiano, A. Silipo, Y. Desaki, D. Garozzo, R. Lanzetta, N. Shibuya and A. Molinaro, Carbohydr. Res., 2016, 427, 38-43.

3 B. Li, B. P. Liu, C. L. Shan, M. Ibrahim, Y. S. Lou, Y. L. Wang, G. L. Xie, H. Y. Li and G. H. Sun, Pest Manage. Sci., 2013, 69, 312-320.

4 S. Perumalsamy, M. Bharani, M. Sudha, P. Nagarajan, L. Arul, R. Saraswathi, P. Balasubramanian and J. Ramalingam, Plant Breed., 2010, 129, 400-406.

5 P. Y. Wang, L. Zhou, J. Zhou, Z. B. Wu, W. Xue, B. A. Song and S. Yang, Bioorg. Med. Chem. Lett., 2016, 26, 1214-1217.

6 A. G. De Oliveira, L. S. Murate, F. R. Spago, L. D. Lopes, J. P. D. Beranger, J. A. B. S. Martin, M. A. Nogueira, J. C. P. Mello, C. G. T. D. Andrade and G. Andrate, Biol. Control, 2011, 56, 125-131.

7 T. R. Gottwald, X. Sun, T. Riley, J. H. Graham, F. Ferrandino and E. L. Taylor, Phytopathology, 2002, 92, 361-377.

8 T. B. Adhikari, R. C. Basnyat and T. W. Mew, Plant Dis., 1999, 83, 46-50.

9 Z. Ji, C. Ji, B. Liu, L. Zou, G. Chen and B. Yang, Nat. Commun., 2016, 7, 13435-13444.

10 L. F. Zou, Y. R. Li and G. Y. Chen, Agric. Sci. China, 2011, 10, 1139-1150.

11 L. F. Zou, X. P. Wang, Y. Xiang, B. Zhang, Y. R. Li and J. S. Wang, Appl. Environ. Microbiol., 2006, 72, 6212-6224.

12 M. H. Chen, Z. Chen, B. A. Song, P. S. Bhadury, S. Yang, X. J. Cai, D. Y. Hu, W. Xue and S. Zeng, J. Agric. Food Chem., 2009, 57, 1383-1388.

13 X. H. Gan, D. Y. Hu, P. Li, J. Wu, X. W. Chen, W. Xue and B. A. Song, Pest Manage. Sci., 2016, 72, 534-543.

14 X. H. Gan, D. Y. Hu, Y. J. Wang, L. Yu and B. A. Song, J. Agric. Food Chem., 2017, 35, 665-672.

15 P. Y. Wang, L. Zhou, J. Zhou, Z. B. Wu, W. Xue, B. A. Song and S. Yang, Bioorg. Med. Chem. Lett., 2016, 26, 1214-1217.

16 X. Wang, P. Li, Z. Li, J. Yin, M. He, W. Xue, Z. Chen and B. A. Song, J. Agric. Food Chem., 2013, 61, 9575-9582.

17 X. M. Zhong, X. B. Wang, L. J. Chen and W. Xue, Chem. Cent. J., 2017, 11, 106.

18 S. Perumalsamy, M. Bharani, M. Sudha, P. Nagarajan, L. Arul, R. Saraswathi, P. Balasubramanian and J. Ramalingam, Plant Breed., 2010, 129, 400-406.

19 Y. Q. Hu, S. Zhang, Z. Xu, Z. S. Lv, M. L. Liu and L. S. Feng, Eur. J. Med. Chem., 2017, 141, 335-345.

20 Y. J. Lin, Z. L. He, E. N. Rosskopf, K. L. Conn, C. A. Powell and G. Lazarovits, Plant Dis., 2010, 94, 201-206. 
21 R. Schobert, B. Biersack and A. Dietrich, J. Med. Chem., 2009, 52, 241-246.

22 S. Vogel, M. Barbic and J. Guido, Eur. J. Med. Chem., 2010, 45, 2206-2213.

23 V. Tomar and G. Bhattacharjee, Eur. J. Med. Chem., 2010, 45, 745-751.

24 P. L. Zhao, C. L. Liu, W. Huang, Y. Z. Wang and G. F. Yang, J. Agric. Food Chem., 2007, 55, 5697-5700.

25 R. Sribalan, G. Banuppriya, M. Kirubavathi, A. Jayachitra and G. Padmini, Bioorg. Med. Chem. Lett., 2016, 26, 5624-5630.

26 G. Pasquale, G. P. Romanelli, J. C. Autino, J. García, V. O. Erlinda and P. R. Duchowicz, J. Agric. Food Chem., 2012, 60, 692-697.

27 S. Attar, Z. O'Brien, H. Alhaddad, M. L. Golden and A. G. Urrea, Bioorg. Med. Chem., 2011, 19, 2055-2073.

28 D. Coskun, M. Erkisa, E. Ulukaya, M. F. Coskun and F. Ari, Eur. J. Med. Chem., 2017, 136, 212-222.

29 X. H. Gan, D. Y. Hu, Y. J. Wang, L. Yu and B. A. Song, J. Agric. Food Chem., 2017, 65, 4367-4377.

30 A. L. Cole, S. Hossain and A. M. Cole, Bioorg. Med. Chem., 2016, 24, 2768-2776.

31 J. F. Li, D. Li, Y. M. Xu, Z. B. Guo, X. Liu, H. Yang, L. C. Wu and L. S. Wang, Bioorg. Med. Chem. Lett., 2017, 27, 602-606.

32 S. J. William, J. H. Melanie, A. S. Stacey and E. M. Rockafellow, J. Org. Chem., 2009, 74, 2765-2770.

33 M. K. Parai, G. Panda, V. Chaturvedi, Y. K. Manju and S. Sinha, Bioorg. Med. Chem. Lett., 2007, 18, 289-292.

34 A. M. Isloor, B. Kalluraya and K. Sridhar, Eur. J. Med. Chem., 2010, 45, 825-830.

35 M. B. Félix, E. R. Souza, M. de Lima, D. K. G. Frade, V. d. L. Serafim and M. R. de Oliveira, Bioorg. Med. Chem. Lett., 2016, 24, 3972-3977.

36 D. H. Pandya, J. A. Sharma, H. B. Jalani, A. N. Pandya, V. Sudarsanam, S. Kachler and K. K. Vasu, Bioorg. Med. Chem. Lett., 2015, 25, 1306-1309.

37 R. Wang, X. Y. Zhi, J. Li and H. Xu, J. Agric. Food Chem., 2015, 63, 6668-6674.
38 R. F. Sun, Z. W. Wang, Y. Q. Li, L. X. Xiong, Y. X. Liu and Q. M. Wang, J. Agric. Food Chem., 2013, 61, 517-522.

39 K. A. K. Musa and L. A. Eriksson, J. Phys. Chem. B, 2009, 113, 11306-11313.

40 R. M. Mohareb, M. Y. Zaki and N. S. Abbas, Steroids, 2015, 98, 80-91.

41 S. G. Gallego, M. J. Serramía, E. Arnaiz, L. Díaz, M. A. MuñozFernández, P. Gómez-Sal, M. F. Ottaviani and R. Gómez, Eur. J. Med. Chem., 2011, 10, 1657-1665.

42 Z. Wang, D. W. Kang, M. Chen, G. C. Wu, D. Feng, T. Zhao, Z. X. Zhou, Z. P. Huo and X. Y. Liu, Chem. Biol. Drug Des., 2018, 92, 2009-2021.

43 N. K. Duddukuri, S. Thatikonda, C. Godugu, R. A. Kumar and N. Doijad, ChemistrySelect, 2018, 3, 6859-6864.

44 J. Zhang, F. Yang, Z. T. Qiao, M. Y. Zhu and H. C. Zhou, Bioorg. Med. Chem. Lett., 2016, 26, 5797-5801.

45 B. Prasad, R. Adepu, S. Sandra, D. Rambabu, G. Rama Krishna, C. M. Reddy, G. S. Deora, P. Misra and M. Pal, Chem. Commun., 2012, 48, 10434-10436.

46 X. Wang, P. Li, Z. N. Li, J. Yin, M. He, W. Xue, Z. W. Chen and B. A. Song, J. Agric. Food Chem., 2013, 61, 9575-9582.

47 P. Li, D. Y. Hu, D. D. Xie, J. X. Chen, L. H. Jin and B. A. Song, J. Agric. Food Chem., 2018, 66, 3093-3100.

48 X. H. Ruan, C. Zhang, S. C. Jiang, T. Guo, R. J. Xia, Y. Chen, X. Tang and W. Xue, Molecules, 2018, 23, 3132-3142.

49 J. Chen, J. Shi, L. Yu, D. Liu, X. H. Gan, B. A. Song and D. Y. Hu, J. Agric. Food Chem., 2018, 66, 5335-5345.

50 Z. X. Wu, J. Zhang, J. X. Chen, J. K. Pan, L. Zhao, D. Y. Liu, A. W. Zhang, J. Chen, D. Y. Hu and B. A. Song, Pest Manage. Sci., 2017, 73, 2079-2089.

51 L. J. Chen, T. Guo, R. J. Xia, X. Tang, Y. Chen, C. Zhang and W. Xue, Molecules, 2019, 24, 925-937.

52 J. Zhou, Q. Q. Tao, P. Y. Wang, W. B. Shao, Z. B. Wu, Z. Li and S. Yang, Bioorg. Med. Chem. Lett., 2018, 28, 1742-1746.

53 X. Y. Li, J. Liu, X. Yang, Y. Ding, J. Wu, D. Y. Hu and B. A. Song, Bioorg. Med. Chem., 2015, 23, 3629-3637.

54 C. J. Wienken, P. Baaske, U. Rothbauer, D. Braun and S. Duhr, Nat. Commun., 2010, 1, 100-107. 